\section{Preview: 2015 Materials Research Society Fall Meeting \& Exhibit}

\author{
Hynes Convention Center and Sheraton Boston \\ Hotel, Boston, Massachusetts \\ Meeting: November 29-December 4 \\ Exhibit: December 1-3 \\ www.mrs.org/fall2015
}

$\mathrm{T}$ he Materials Research Society (MRS) will hold its 2015 Fall Meeting at the Hynes Convention Center and the Sheraton Boston Hotel in Boston, Mass., November 29-December 4, 2015. The Meeting will include a technical program, tutorials, a plenary session, an award ceremony, poster sessions, a career fair, and other special activities. MRS Advances (symposium proceedings) will be published and made available free online to MRS members.

MRS Meetings focus on the interdisciplinary nature of materials research worldwide. The program's 55 symposia address leading-edge research and capture the extraordinary progress in materials science and technology, organized into the following clusters.

Advances in the design, synthesis, and processing of biomaterials and soft matter continue to expand the use of these materials in a wide variety of applications. The cluster on Biomaterials and Soft Materials captures this progress, with symposia aimed at stretchable and active polymers and composites for energy and medicine; engineering and application of bioinspired materials; multifunctionality in polymer-based materials; and materials science, technology, and devices for cancer modeling, diagnosis, and treatment.

In the cluster on Nanomaterials and Synthesis, symposia concerning the synthesis and function of a broad range of nanomaterials will be available. Topics of interest include micro- and nanoscale processing of materials for biomedical devices; nanocarbon materials-1D to 3D; plasmonic nanomaterials for energy conversion; and magnetic nanomaterials for biomedical and energy applications.
The cluster on Mechanical Behavior and Failure of Materials features shapeprogrammable materials; mechanical behavior at the nanoscale; microstructure evolution and mechanical properties in interface-dominated metallic materials; and materials under extreme environments.

Symposia concerning the utilization of a broad range of advanced materials in electronics and photonics devices and applications will be available, from molecularly ordered organic and polymer semiconductors to organic electronics. In this cluster on Electronics and Photonics, recent advances are covered in diamond electronics, sensors, and biotechnology; beyond graphene-2D materials and their applications; optical metamaterials; and materials and technology for nonvolatile memories.

Materials science advances driving improvements in energy conversion and storage are highlighted in the Energy and Sustainability (MRS/E-MRS Bilateral Energy Conference) cluster. Symposia will focus on advances in flexible devices for energy conversion and storage; thin-film and nanostructure solar-cell materials and devices for next-generation photovoltaics; nanomaterials-based solar energy conversion; and catalytic materials for energy.

Theory, Characterization, and Modeling is the focus of another cluster. Symposia will discuss topology in

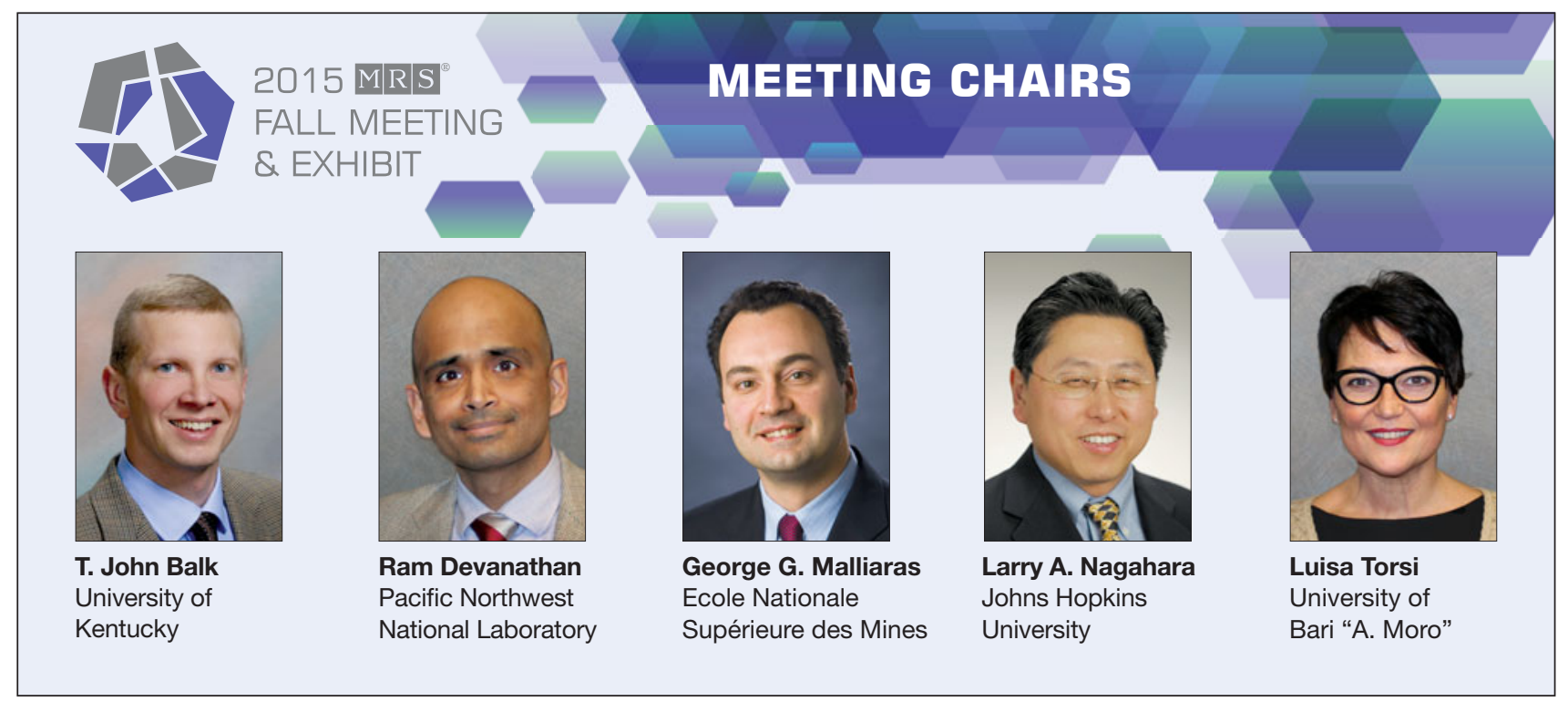




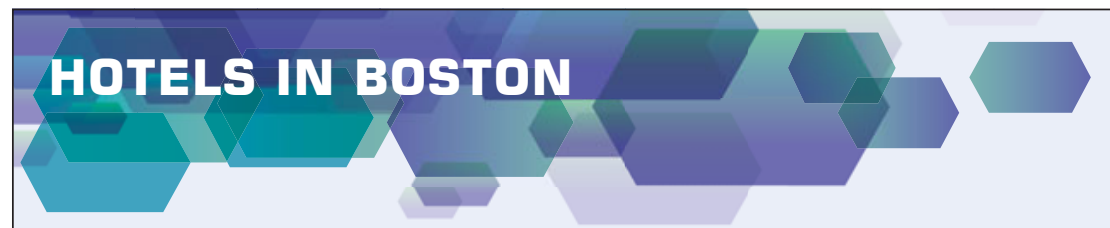

MRS receives meeting space at a greatly discounted rate as a result of contracting a large block of sleeping rooms at the official meeting hotels. In order to keep meeting costs as low as possible and minimize the financial risk to MRS, we encourage you to utilize official MRS housing while you are attending an MRS meeting. Hotels offering discounted rates for the 2015 MRS Fall Meeting are listed below. To make reservations, visit www.mrs.org/fall-2015-hotels.

- Sheraton Boston Hotel 39 Dalton St., Boston, MA 02199 617-236-2000

Rate: \$197/single, \$207/double—plus applicable taxes and fees; additional persons are $\$ 20 /$ each Deadline: October 13, 2015

- Boston Marriott Copley Place 110 Huntington Ave., Boston, MA 02116 617-236-5800

Group Rate: \$191/single, \$207/double, \$217/ triple, \$227/quad—plus applicable taxes and fees Deadline: November 4, 2015

- Hilton Boston Back Bay Hotel 40 Dalton St., Boston, MA 02115 617-236-1100

Group Rate: \$206/single, \$206/double, \$226/ triple, \$226/quad—plus applicable taxes and fees Deadline: November 6, 2015

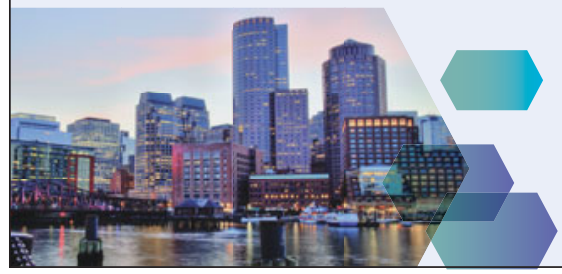

- The Westin Copley Place 10 Huntington Ave., Boston, MA 02116 617-262-9600

Rate: \$193/single, \$203/double—plus applicable taxes and fees; additional persons are \$20/each Deadline: November 6, 2015

- The Boston Park Plaza Hotel \& Towers 50 Park Plaza at Arlington St., Boston, MA 02116 800-225-2008

Group Rate: \$165/single, \$165/double—plus applicable taxes and fees; additional persons are $\$ 20 /$ each

Deadline: November 6, 2015

- Embassy Suites Boston at Logan Airport 207 Porter St., Boston, MA 02128 617-567-5000 Group Rate: \$139/single—plus applicable taxes and fees; additional $\$ 10 /$ person per room Deadline: November 18, 2015

- The Colonnade Hotel 120 Huntington Ave., Boston, MA 02116 617-424-7000 Group Rate: \$197/single, \$207/double, \$227/ triple, \$247/quad—plus applicable taxes and fees Deadline: November 6, 2015 materials science; frontiers in scanning probe microscopy; advanced atomistic algorithms, theoretical studies and neutron scattering of liquids and glassy soft matter; and modeling and theory-driven design of soft materials.

\section{Plenary session and awards}

The Plenary Session will be held on Monday, November 30, at 6:30 pm, in the Sheraton Boston Hotel, second floor, Grand Ballroom. This year's plenary speaker is Chad A. Mirkin, Director of the International Institute for Nanotechnology and the George B. Rathmann Professor of Chemistry; professor of chemical and biological engineering; professor of biomedical engineering; professor of materials science and engineering; and professor of medicine at Northwestern University. Mirkin will discuss how nature utilizes nucleic acids to encode, transmit, and express genetic information in his talk entitled "Programmable Materials and the Nature of the DNA Bond."

The Award Ceremony will convene on Wednesday, December 2, at 6:30 pm, in the Sheraton Grand Ballroom. The David Turnbull Lectureship Award, MRS Medal, Materials Theory Award, MRS Postdoctoral Awards, Graduate Student Gold and Silver Awards, and Von Hippel Award will be presented.

Named after the late David Turnbull of Harvard University, the David Turnbull Lectureship Award recognizes the career contribution of a scientist to fundamental understanding of the science of materials through experimental and/or theoretical research, as well as through writing and lecturing. Jacob Klein, of the Department of Materials and Interfaces at the Weizmann Institute of Science, Rehovot, Israel, is cited, "for discoveries which transformed our understanding of soft matter and interfaces, through sustained research, inspirational lecturing and academic leadership."

The MRS Medal recognizes an exceptional achievement in materials research in the past 10 years, and will be awarded to Richard B. Kaner, Department of Chemistry, at the University of California-Los Angeles. He is cited "for the discovery of efficient methods to synthesize water dispersible conducting polymer nanofibers and their applications in sensors, actuators, molecular memory devices, catalysis, and the novel process of flash welding."

The Materials Theory Award recognizes exceptional advances made by materials theory to the fundamental understanding of the structure and behavior of materials. This award, endowed by Toh-Ming Lu and GwoChing Wang, is intended to honor both those who have pioneered the development of a new theoretical approach and those who have used existing approaches to provide significant new insight into materials behavior. This year's recipient is Steven G. Louie, Department of Physics, University of California-Berkeley, "for his seminal contributions to the development of $a b$ initio methods for and the elucidation of many-electron effects in electronic excitations and optical properties of solids and nanostructures."

The MRS Postdoctoral Awards recognize postdoctoral scholars who show exceptional promise, which may include excellence in scientific research, leadership, advocacy, outreach, or teaching during their postdoctoral assignment.

The Fred Kavli Distinguished Lectureship in Nanoscience, which supports scientific research, honors scientific achievement, and promotes public understanding of scientists and 
their work, will be presented by Yi Cui from Stanford University.

The Kavli Early Career Award in Nanoscience recognizes significant novel contributions to materials science by a young researcher in the early stages of his/her career. This year's recipient is Ali Khademhosseini, Harvard-MIT Division of Health Sciences and Technology.

The award ceremony will be followed by the Von Hippel Award address. Named after Arthur R. von Hippel (1898-2003), the award recognizes brilliance and originality of intellect, combined with vision that transcends the boundaries of conventional scientific disciplines. Richard H. Friend, Optoelectronics Group, Cavendish Laboratory at the University of Cambridge, will be recognized "for pioneering research on highly original materials phenomena and device concepts, enabled by polymeric semiconducting materials, and imprinting an indelible influence on contemporary materials science and the new field of plastic electronics."

\section{Special sessions and events}

Symposium $\mathbf{X}$ talks provide Meeting attendees with an overview of leadingedge topics. Arumugam Manthiram of The University of Texas at Austin, USA, will present "Electrical Energy Storage: Materials Challenges and Prospects" on Monday, November 30; Zhenan Bao of Stanford University, USA, will discuss "Skin Inspired Organic Electronic Materials and Devices" on Tuesday,
December 1; Joanna Aizenberg of Harvard University, USA, will address "Biologically Inspired Engineering: From Discovery to Technological Innovation" on Wednesday, December 2; and Christopher Ober of Cornell University, USA, will present "Fifty Years of Moore's Law: Towards Fabrication at Molecular Dimensions" on Thursday, December 3.

Poster sessions, an integral feature of MRS meetings, will be held during the evenings. The meeting chairs will award prizes of up to $\$ 500$ for the best posters during each session.

The Technology Innovation Forum will be held on Wednesday, December 2, at 9:00 am, in the Hynes Convention Center, Level 2, The Hub Stage. This forum features innovation and investor

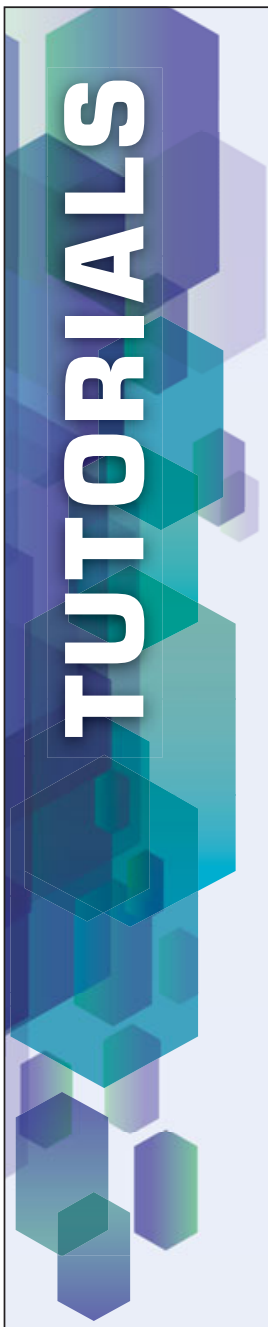

\section{SUNDAY, NOVEMBER 29}

The 2015 MRS Fall Meeting will feature 11 tutorials on Sunday, November 29, covering a variety of topics to complement the scientific sessions, along with an additional broader impact tutorial exploring nontraditional information acquisition in materials science. The tutorials are complimentary to all attendees.

An option to purchase tutorial notes, now available in color, at the preregistration price of $\$ 35$ will be available on the registration form (posted on the MRS website in late-September). After the preregistration period ends, notes will be priced at $\$ 45$ and will be available at the Publications Desk on-site at the Meeting.

A Engaged Learning Approaches for Current and Future Educators (Preregistration required; tutorial notes will not be available for purchase.) 8:00 am-12:00 pm Hynes Convention Center | Room 202

H Biodegradation of Polymers 1:30 pm-5:00 pm Hynes Convention Center | Room 201

K Emerging Technologies Encompassing the Complexity of Cancer 1:30 pm-4:00 pm Hynes Convention Center | Room 200

P Emerging Applications of Nanowires in Life Sciences and Optoelectronics 1:30 pm-5:00 pm Hynes Convention Center | Room 203

JJ Electric and Magnetic Field Responses of Magnetoelectric Materials 1:30 pm-5:00 pm Hynes Convention Center | Room 207

NN New Developments in Perovskite Solar CellsFrom Fundamentals to Applications 1:30 pm-5:00 pm Hynes Convention Center | Room 210
RR Introduction to Wide-Bandgap Materials for Power Electronics and Solid-State Lighting 8:30 am-5:00 pm Hynes Convention Center | Room 206

YY Long Timescale Atomic Simulations in Materials Science 9:00 am-5:00 pm Hynes Convention Center | Room 208

High-Throughput Experiment, Simulation and Data Analytics 8:30 am-5:00 pm Hynes Convention Center | Room 209

DDD A Primer on Static and Dynamic Control of Transition Metal-Oxide Function 1:30 pm-5:00 pm Hynes Convention Center | Room 204

BI-T1 XXIst Century Tools for Accelerating Scientific Research 1:30 pm-5:00 pm Hynes Convention Center | Room 202 
topics around materials for light emission and instrumentation using light for materials characterization. The keynote talk will feature a case study on LED lighting, including the trials, tribulations, successes, and fun involved in exploiting research to produce substantial cost savings and enable the worldwide use of LED lighting. The keynote speaker is Sir Colin Humphreys, University of Cambridge, whose talk addresses "Bridging the Gap between Science and a Real Product: A Case Study on LED Lighting."

The Women in Materials Science and Engineering Breakfast will be held on Wednesday, December 2, at 7:00 am. Delia Milliron, from The University of Texas at Austin, will lead an interactive session about a materialsresearch-filled journey with a talk entitled "Off the Beaten Path: Path Making in the Stem Landscape."

Government agency program managers will present information on funding opportunities in the materials science and technology research areas in Government Agency Presentations: Materials Research Support. The presentations will be held on Tuesday, December 1, and Thursday, December 3, 5:45-8:00 pm, in the Sheraton Boston Hotel. The tentative list of presenting agencies includes the National Science Foundation Division of Materials Research; US Department of Energy Office of Basic Energy Sciences; ElectroOptics Infrared Discovery and Invention, Office of Naval Research; and the Air Force Office of Scientific Research.

The 2015 MRS Fall Meeting Career Fair will be held in the Hynes Convention Center Exhibit Hall Tuesday through Thursday. The Career Fair will provide an opportunity for Meeting participants and top employers to discuss career opportunities and will feature recruiters and on-site interviews, career development

\begin{tabular}{|l|c|c|}
\hline \multicolumn{3}{|c|}{2015 MRS FALL MEETING REGISTRATION RATES } \\
\hline & $\begin{array}{c}\text { PREREGISTRATION } \\
\text { before 5:00 pm EST } \\
\text { November 13, 2015 }\end{array}$ & $\begin{array}{c}\text { ON-SITE REGISTRATION } \\
\text { after 5:00 pm EST } \\
\text { November 13, 2015 }\end{array}$ \\
\hline Meeting Registration & $\$ 625$ & $\$ 750$ \\
\hline Meeting Registration with MRS Member Discount & $\$ 505$ & $\$ 630$ \\
\hline Student Registration & $\$ 135$ & $\$ 165$ \\
\hline Student Registration with MRS Member Discount & $\$ 110$ & $\$ 140$ \\
\hline Unemployed & $\$ 135$ & $\$ 165$ \\
\hline Retired & $\$ 165$ & $\$ 195$ \\
\hline
\end{tabular}

All 2015 MRS Fall Meeting registrations include MRS membership through December 2016.

sessions, and resume critiques and mock interviews. Students, postdocs, and seasoned professionals are all welcome.

A Materials Hackathon will be held Monday morning through Tuesday at the 2015 MRS Fall Meeting. In 24 hours, MatHack participants will make 30-second pitches of ideas for new materialsrelated software, form teams around those ideas, bring the concepts to life with working code, and present the results to a panel of judges from across the materials field. Prizes will be awarded, and the results will be open-sourced and hosted for others to download.

A professional development workshop titled "Get Your Voice on the Table: Physical and Vocal Presence at the Meeting" will be held on Sunday, November 29, 1:00-4:00 pm, in the Sheraton Boston Hotel. The speaker is Nancy Houfek, an independent consultant for the Committee on the Advancement of Women Chemists, an organization dedicated to supporting and promoting the careers of women in the chemical sciences.

The popular Science as Art competition will be held again at this Meeting. The competition is open to all registered Meeting attendees, with entries to be on display in the Hynes Convention Center. Multiple first-place and second-place awards of $\$ 400$ and $\$ 200$, respectively, will be presented. Guidelines and deadlines for entry will be available on the 2015 MRS Fall Meeting website.

A number of other events will take place throughout the Meeting, including other professional development opportunities. To stay up to date with additional events and activities, access www.mrs.org/fall2015.

\section{For more information}

The deadline to preregister for the meeting is November 13, 2015, 5:00 pm (EST). International travelers are reminded to allow ample time to obtain a visa, if necessary. For additional details about the Meeting, contact MRS Member Services, Materials Research Society, 506 Keystone Drive, Warrendale, PA 150867573, USA; email info@mrs.org, and tel. 724-779-3003. Details of various events and activities will be published in the 2015 MRS Fall Meeting Program \& Exhibit Guide available on-site. The MRS website can be accessed for updated information on confirmed talks and details of special events, for more information on obtaining a visa, and for preregistration at www.mrs.org/fall2015.

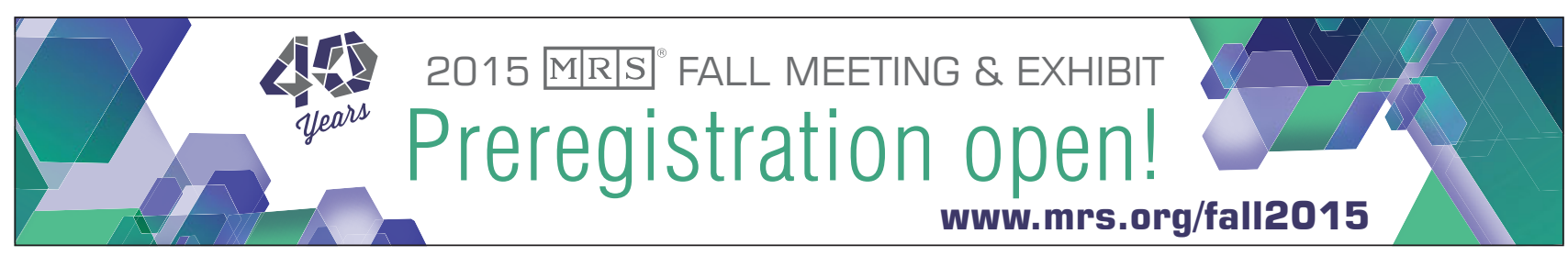

